\title{
Which Patients Are a Better Candidate of Laparoscopic Repair in Obturator Hernia Patients?
}

Jae Seung Kwak, M.D., Sang Eok Lee, M.D., Ph.D., Si Min Park, M.D., Seung Jae Lee, M.D., Seong Uk Kwon, M.D., In Eui Bae, M.D., Nak Song Sung, M.D., Ju Ik Moon, M.D., Dae Sung Yoon, M.D., In Seok Choi, M.D., Won Jun Choi, M.D.

Department of General Surgery, Konyang University Hospital, Daejeon, Korea

Purpose: Obturator hernia is a difficult disease to diagnose. If a surgical treatment is delayed in obturator hernia, a bowel resection may be required due to strangulation. The surgical treatment of this disease is to use a classical laparotomy. Recently, the laparoscopic approach has been reported and reviewed for efficiency. We checked the indicators that determine the most appropriate surgical method according to the patient's condition.

Methods: In the study, a single-institution, retrospective analysis of surgical patients undergoing an obturator hernia surgery between 2003 and 2018 was performed. The patients were divided into a laparoscopic group (5 patients underwent laparoscopic repair; no intestinal resection) and an open group (13 patients who underwent open repair; 10 with and 3 without intestinal resection). The outcomes were compared between the groups. We analyzed the relevant factors that could predict the proper method of surgery.

Results: A total 18 patients were included in the study. All patients were female, with body mass index (BMI) of under $21 \mathrm{~kg} / \mathrm{m}^{2}$. Of the various factors, only the WBC and CRP counts were the factors that had shown significant differences between the two groups. It is noted that patients with open surgery had a higher WBC counts (10406 versus $6520 / \mu 1 ; p=0.011)$ and CRP counts (7.84 vs. 0.32 $\mathrm{mg} / \mathrm{dl} ; p=0.027$ ).

Conclusion: Obturator hernia can be treated with a laparoscopic surgery. The choice of surgical treatment can be considered in advance through the review of the patient's WBC count or CRP count.
Received February 19, 2020

Revised March 24, 2020

Accepted April 20, 2020

Corresponding author

Sang Eok Lee

Department of General Surgery,

Konyang University Hospital, 158

Gwanjeodong-ro, Seo-gu, Daejeon

35365, Korea

Tel: +82-42-600-8956

Fax: +82-42-543-8956

E-mail: srglee@hanmail.net ORCID:

https://orcid.org/0000-0002-9956-7693

Keywords: Obturator hernia, Laparoscopy, Hernia repair, Laparotomies

This is an Open Access article distributed under the terms of the Creative Commons Attribution Non-Commercial License (http:// creativecommons.org/licenses/by-nc/4.0/) which permits unrestricted non-commercial use, distribution, and reproduction in any medium, provided the original work is properly cited.

Copyright $\odot 2020$ The Journal of Minimally Invasive Surgery. All rights reserved.

\section{INTRODUCTION}

Obturator hernia $(\mathrm{OH})$ is a rare disease and does account for $0.07 \sim 1 \%$ of all hernias. ${ }^{1}$ It tends to occur in elderly, and with thin and multiparous females. As the patient's symptoms are usually nonspecific and the physical findings are obscure, a diagnosis of $\mathrm{OH}$ could be delayed in most cases. Delays in operative intervention can contribute to the increased need for a resection of the gangrenous bowel as seen in up to $50 \%$ of $\mathrm{OH}$ repairs; and in that case, the perioperative mortality rates in such settings can be as high as $70 \% .^{2-4}$ However, early CT scanning increase speed of diagnosis, and therefore reduce complications such as bowel ischemia and the need for bowel resection at the time of surgery. ${ }^{5}$

The surgical treatment of $\mathrm{OH}$ is to utilize a classical laparotomy with repair of the hernia and bowel resection, in the 
case of a bowel ischemia. Recently, the laparoscopic approach has been increasingly adopted, and is reported that have lower complication and incidence or result of mortality than when using the open operation. ${ }^{6}$ However, it is highly likely that laparoscopic procedures utilized will be difficult to complete the operation if the bowel resection and anastomosis are required in an obturator hernia, which it is noted that the conversion rate is $7 \%$ in $\mathrm{OH}$ repair as compared to $1.8 \%$ in the repair of a strangulated inguinal hernias laparoscopically.

In our study, we analyzed the result of laparoscopic operation and indicators that could affect the surgical method according to the patient's condition.

\section{MATERIALS AND METHODS}

\section{Patients}

In this study, there was a single-institution, retrospective analysis of surgical patients undergoing an obturator hernia surgery (laparoscopic surgery versus open surgery) between 2003 and 2018 was performed. Of the total 18 patients, 5 patients were completed the operation with a laparoscopic repair, 5 patients were switched to open surgery and 8 were completed the operation with open surgery. In this study, the patients who had open conversion were included in open surgery group. Likewise, the patients were divided into a laparoscopic group (5 patients underwent laparoscopic repair; with no intestinal resection) and an open group (13 patients who underwent open repair; 10 with and 3 without intestinal resection, open conversion cases were also included in this group). It is noted that the patient's characteristics, surgical outcomes, incidence of complications and mortality were compared between the groups. At that time we also analyzed factors that could predict the proper method of the proposed surgery. The choice of procedure, laparoscopic or open surgery, was at the surgeon's discretion. Therefore, patients with severe conditions or patients with severe intestinal dilation or surgeons with not familiar with laparoscopic approach were generally allocated to the open procedure in this retrospective study.

\section{Surgical procedure (for laparoscopic repairs)}

Totally extraperitoneal (TEP) repair for obturator hernia was performed under general anesthesia. The procedures are described as follows. We used a $10 \mathrm{~mm}$ port for the camera $(0$ degree videoscope) just below the umbilicus and two additional trocar ports are placed in the about $5 \mathrm{~cm}$ below the umbilicus, and suprapubic at $3 \mathrm{~cm}$ above the symphysis pubis with 5 $\mathrm{mm}$ trocar ports under direct vision. After a full dissection of the preperitoneal space, the herniated sac was retracted using atraumatic forceps (Fig. 1). The mesh was inserted through the camera port. It was positioned on the obturator foramen and
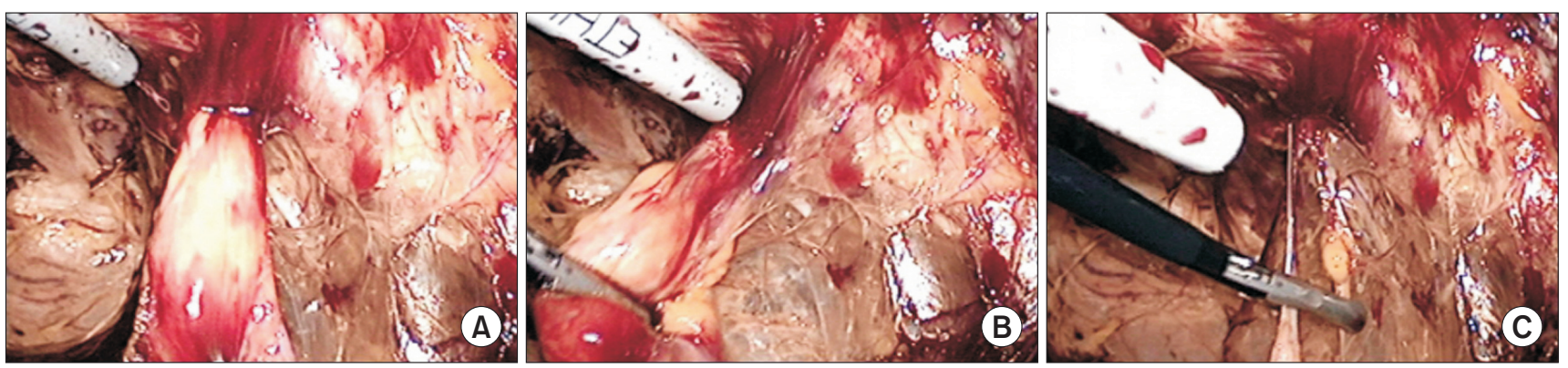

Fig. 1. Reduction was performed by pulling the hernia sac. (A) Identification of the herniated hernia sac. (B) Reduction of the hernia sac from obturator foramen. (C) After reduction of the hernia sac.
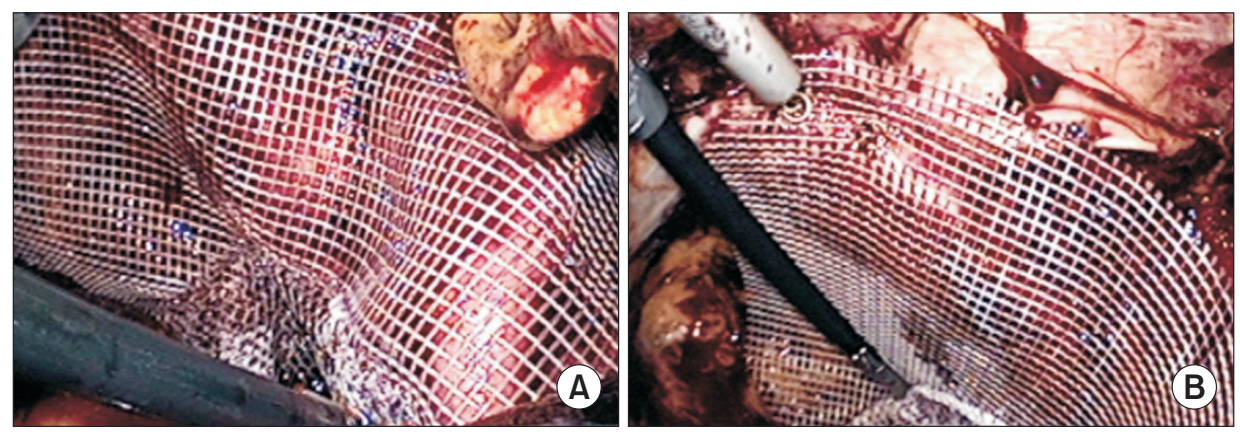

Fig. 2. Mesh apply. (A) Mesh was positioned on the obturator foramen and completely covered. (B) Mesh was secured to ligament around the pubic tubercle with a tacker. 
completely covered, and it was secured to ligament around symphysis pubis with tacker (Fig. 2). Small bowel viability was confirmed through intra-abdominal laparoscopic exploration after TEP repair. If the segment was non-viable, then a laparoscopic-assisted resection and anastomosis was done $\mathrm{ex}^{-}$ tracorporeally (minilaparotomy or conversion).

In patients undergoing laparotomy, the obturator foramen was closed by the use of continuous sutures or prosthesis.

This was a retrospective study and approved by the Konyang University Hospital Institutional Review Board (KYUH 201908-002).

\section{Statistical analysis}

The entire statistical analysis was performed using IBM SPSS Statistics 25.0. The t-test was used for the review of independent samples comparison of continuous variables. The Chi-square test was used to compare categorical variables. Also, the $p<0.05$ was considered to denote a statistical significance.

\section{RESULTS}

\section{Patients characteristic}

The 18 patients included and baseline patient characteristics are summarized in Table 1. There were two groups in which one was completed with $\mathrm{OH}$ surgery through laparoscopic approach, laparoscopic group, the other was either was open or switched from laparoscopic to an open surgery. All patients in the study were females. The mean age was $84.8 \pm 6.2$ years (range 74 94 years); the mean weight was $38.5 \pm 5.5 \mathrm{~kg}$ (range 28 47 kg); the mean body mass index was 17.6 \pm 2.2 $\mathrm{kg} / \mathrm{m}^{2}$ (range 12.7 $20.4 \mathrm{~kg} / \mathrm{m}^{2}$ ); Three patients had a history of previous abdominal operation. In this relation, the mean preoperative period after the onset of symptoms was $12.1 \pm 22.5$ days (range 1 97). Most patients had intestinal obstruction $\mathrm{ex}^{-}$ cept two patients. Preoperative CT examination was done and confirmed the diagnosis of obturator hernia in all patients.

Table 1. Patient characteristics

\begin{tabular}{|c|c|c|c|c|c|c|c|c|c|c|}
\hline Case & Age & Sex & $\begin{array}{c}\text { BMl } \\
\left(\mathrm{kg} / \mathrm{m}^{2}\right)\end{array}$ & $\begin{array}{l}\text { Previous } \\
\text { operation }\end{array}$ & Location & CT & lleus & Emergency & $\begin{array}{l}\text { Symptom } \\
\text { to operation } \\
\text { day (days) }\end{array}$ & $\begin{array}{l}\text { WBC } \\
(/ \mu l)\end{array}$ \\
\hline 1 & 77 & $\mathrm{~F}$ & - & - & Left & + & + & + & 10 & 15440 \\
\hline 2 & 90 & $\mathrm{~F}$ & 14.27 & - & Right & + & + & + & 6 & 6140 \\
\hline 3 & 88 & $\mathrm{~F}$ & 20.41 & - & Left & + & + & + & 12 & 10210 \\
\hline 4 & 87 & $F$ & 16.65 & - & Right & + & + & + & 5 & 3900 \\
\hline 5 & 78 & $\mathrm{~F}$ & 18.94 & - & Right & + & - & - & 97 & 6100 \\
\hline 6 & 94 & $\mathrm{~F}$ & 17.48 & - & Right & + & - & - & 31 & 14000 \\
\hline 7 & 75 & $\mathrm{~F}$ & 18.07 & - & Left & + & + & + & 3 & 11400 \\
\hline 8 & 79 & $\mathrm{~F}$ & 19.56 & - & Right & + & + & + & 5 & 16900 \\
\hline 9 & 94 & $F$ & 17.86 & - & Left & + & + & + & 1 & 9100 \\
\hline 10 & 85 & F & 16.88 & + & Left & + & + & + & 1 & 11900 \\
\hline 11 & 82 & $F$ & 12.78 & - & Right & + & + & + & 2 & 6600 \\
\hline 12 & 87 & $\mathrm{~F}$ & 17.90 & + & Left & + & + & + & 2 & 9100 \\
\hline 13 & 92 & $\mathrm{~F}$ & 17.78 & & Left & + & + & + & 5 & 6300 \\
\hline 14 & 86 & $\mathrm{~F}$ & 14.67 & - & Right & + & + & + & 11 & 11100 \\
\hline 15 & 91 & $\mathrm{~F}$ & 20.41 & - & Right & + & + & + & 4 & 13700 \\
\hline 16 & 86 & $\mathrm{~F}$ & 20.08 & + & Right & + & + & + & 2 & 4500 \\
\hline 17 & 83 & $\mathrm{~F}$ & 20.00 & - & Left & + & + & + & 2 & 6600 \\
\hline 18 & 74 & $\mathrm{~F}$ & 16.89 & - & Right & + & + & + & 20 & 4900 \\
\hline
\end{tabular}

$\mathrm{BMI}=$ Body mass index; $\mathrm{WBC}=$ White blood cell; $\mathrm{CT}=$ Computed tomography . 
Table 2. Result of univariate analyses of preoperative clinical variables in the laparoscopic group and open group

\begin{tabular}{|c|c|c|c|}
\hline & $\begin{array}{l}\text { Laparoscopic } \\
\text { group }(n=5)\end{array}$ & $\begin{array}{l}\text { Open group } \\
(\mathrm{n}=13)\end{array}$ & $p$ value \\
\hline Sex (male/female) & $0 / 5$ & $0 / 13$ & - \\
\hline Age, mean (year) & $85.0 \pm 5.2$ & $84.8 \pm 6.8$ & $p=0.965$ \\
\hline BMI, mean $\left(\mathrm{kg} / \mathrm{m}^{2}\right)$ & $17.4 \pm 2.7$ & $17.7 \pm 2.0$ & $p=0.829$ \\
\hline Location (Right/Left) & $3 / 2$ & $7 / 6$ & $p=1.000$ \\
\hline $\begin{array}{l}\text { History of abdominal } \\
\text { surgery }\end{array}$ & $2(40 \%)$ & $2(15 \%)$ & $p=0.172$ \\
\hline WBC, mean $(/ \mu \|)$ & $6520.0 \pm 1655.8$ & $10406.9 \pm 4103.4$ & $p=0.011$ \\
\hline ESR, mean & $25.7 \pm 14.6$ & $32.3 \pm 18.4$ & $p=0.544$ \\
\hline CRP, mean (mg/dl) & $0.3 \pm 0.3$ & $7.8 \pm 8.3$ & $p=0.027$ \\
\hline $\begin{array}{l}\text { Time from Symptom } \\
\text { to operation (days) }\end{array}$ & $21.6 \pm 42.1$ & $8.5 \pm 8.6$ & $p=0.529$ \\
\hline
\end{tabular}

$\mathrm{BMI}=$ body mass index; $\mathrm{WBC}=$ white blood cell; $\mathrm{ESR}=$ erythrocyte sedimentation rate, $\mathrm{CRP}=\mathrm{C}$-reactive protein.

\section{Preoperative variables}

There was no factor statistically significant difference in a review of the preoperative clinical variables (sex, age, BMI, location, history of abdominal surgery) between the two groups, except White blood cell (WBC) and C-reactive protein (CRP) in Table 2.

The WBC was significantly higher in open surgery group with 6520.0 versus $10406.9 / \mu 1, p=0.011$. Additionally, the CRP was also shown to be significantly higher in the open surgery group with 0.3 vs $7.8 \mathrm{mg} / \mathrm{dl}, p=0.027$.

However, there was no significant difference in the time of symptom to operation.

\section{Surgical outcomes}

In this context, it was noted that the operation time was significantly lower in the laparoscopic group $(p<0.001)$ in Table 3. Likewise, the estimated blood loss $(6.2 \mathrm{ml}$ in the laparoscopic group and $68.7 \mathrm{ml}$ in the open group $(p=0.358)$ was more favorable in the laparoscopic group, though the results were not considered to be statistically significant. In the laparoscopic group, there was no bowel resection. In the open group, there were 11 patients who required a bowel resection. The mesh prosthesis was used in 5 patients (100\%) in the laparoscopic, and with 9 patients $(69 \%)$ in the open group $(p=0.278)$.

Incidence of postoperative complications (20 vs. $76 \%$ ) was significantly lower in the laparoscopic group $(p=0.047)$. The postoperative complications in the open group included para-
Table 3. Result of univariate analyses of surgical outcomes between the laparoscopic group and open group

\begin{tabular}{lccc|}
\hline & $\begin{array}{c}\text { Laparoscopic } \\
\text { group }(\mathbf{n}=5)\end{array}$ & $\begin{array}{c}\text { Open group } \\
(\mathbf{n}=13)\end{array}$ & $p$ value \\
\hline $\begin{array}{l}\text { Operation time (min) } \\
47 \pm 19.5\end{array}$ & $103.0 \pm 24.5$ & $p<0.001$ \\
$\begin{array}{l}\text { Estimated blood } \\
\text { loss (m)) }\end{array}$ & $6.2 \pm 3.8$ & $68.7 \pm 144.3$ & $p=0.358$ \\
$\begin{array}{l}\text { Bowel resection } \\
\text { Mesh prosthesis }\end{array}$ & $0(0 \%)$ & $11(104 \%)$ & $p=0.002$ \\
\hline Hospital stay & $5 \pm 2.3$ & $24.5 \pm 24.6$ & $p=0.104$ \\
$\begin{array}{l}\text { Postoperative } \\
\text { complication }\end{array}$ & $1(20 \%)$ & $10(76 \%)$ & $p=0.047$ \\
\hline Mortality & 0 & 0 & - \\
\hline Readmission & 0 & 2 & $p=1.000$ \\
\hline
\end{tabular}

lytic ileus ( $n=5)$, pneumonia $(n=3)$, renal dysfunction $(n=2)$, wound infection $(n=2)$, cardiac arrest $(n=1)$, voiding difficulty $(\mathrm{n}=1)$, pseudomembranous colitis (PMC) $(\mathrm{n}=1)$, while the only one in the laparoscopic group was an arrhythmia $(n=1)$. It is noted that there was a readmission of a participant related to the surgery, which was necessary for two patients in the open group. One of the patients had a wound infection which needed to remove a mesh on the operation site, and the other patient is noted to have had a PMC.

\section{DISCUSSION}

The clinical diagnosis of $\mathrm{OH}$ is difficult to determine, due to uncommon incidence, deep location, and infrequent symptoms and signs. The majority of patients fail to complain of obturator neuralgia. Broadly speaking, the hernia sac irritates and compresses obturator nerve within the canal causing medial thigh pain. In this case, the Howship-Romberg sing is the cause of pain radiating down the medial aspect of the thigh to the knee, and is seen less often to be present in the hip due to compression of the anterior division of the obturator nerve. It is noted that this condition is seen in up to $15 \sim 50 \%$ of patients. A palpable mass is found in $20 \%$ of cases in the proximal medial aspect of the thigh. ${ }^{5,8}$ For this reason, The diagnosis of $\mathrm{OH}$ can be delayed, and it can lead to a bowel resection and a high morbidity and mortality rate in patients. ${ }^{2-4}$

In line with this reasoning, early CT imaging can make an early diagnosis with reduced morbidity and mortality associated with obturator hernia. ${ }^{9}$ A review of the abdominal Xray shows evidence of a small bowel obstruction in cases of obstructed OH. Likewise, the USG can show the presence of a hernia located in the inguinal and upper femoral region. To 
begin with, this condition is often misdiagnosed as an inguinal or femoral hernia. In this case, the CT scan is diagnostic in $\mathrm{OH}^{10}$ In this relation, we can take a $\mathrm{CT}$ scan early when the small bowel obstruction is observed in elder and thin women.

The treatment of $\mathrm{OH}$ is determined as a classical laparotomy with repair of the hernia and bowel resection in a case of bowel ischemia. Recently, laparoscopic surgery has become an alternative treatment for $\mathrm{OH}$. The advantage of the use of the laparoscopic technique was associated with a reduced duration of hospital stay and fewer complications for the patient postsurgery. But the superiority of laparoscopic surgery compared with the use of an open surgery was not been established yet, and laparoscopic surgery cannot apply to all cases due to the more challenging technology and longer learning curve. ${ }^{11-15}$ In our study, we were able to confirm the feasibility of laparoscopic surgery and, at the same time, confirm that the use of laparoscopic surgery may be difficult depending on the degree of incarceration/strangulation. Even if the use of a laparoscopic surgery has the benefit of a good result as noted after the surgery, what is more important is to determine the fastest and safest surgical treatment for the patient. ${ }^{16}$ That being noted, we checked a factor that could determine the method of surgery through a review of the preoperative patient conditions. By determining the method of surgery in advance, it is noted that the additional cost and time delay can be reduced, due to changes in the method of surgery that was chosen during the operation. The Jing et al. study recommended a laparoscopic surgery when the patient's symptom is within two days before surgery. ${ }^{12}$ In our study, however, there was no significant difference in time lapse between onset of symptoms and operation between two groups ( $p=0.529,21.6$ vs 8.5 days).

The significant differences of preoperative patient's factors between laparoscopic surgical groups and open surgical groups were noted as WBC and CRP. In the WBC, CRP, that were significantly lower in laparoscopic surgery group $(p=0.011$, 6520.0 vs $10406.9 / \mu \mathrm{l}, \mathrm{WBC}, p=0.027,0.3$ vs. $7.8 \mathrm{mg} / \mathrm{dl}$, CRP). Through this results, we might think that if the WBC and CRP levels are low, there is a high possibility that there is no intestinal strangulation. And we could confirmed the result that there is significant difference between the WBC and the CRP between the group with the bowel strangulation and the group without bowel strangulation.

This result means that if the WBC and CRP are not elevated, then we could consider a laparoscopic surgery method first because the bowel resection which maybe need to change the method of operation will not be needed. The Receiver Operating Characteristic (ROC) curve was drawn to find the cut off value to consider the open operation, but it was difficult to find the meaningful cut off value possibly as a result of the low number of cases.
There were some limitations associated with this study. First, the present study was retrospective in nature and was performed in a single center. Second, the choice of surgery, laparoscopic or open, was at the surgeon's discretion. In other words, the decision was made and tended to have open surgery if the patient has shown severe symptoms. In addition, there was no patient who underwent laparoscopic repair in this case with an intestinal resection. In laparoscopic surgery, all cases requiring intestinal resection were switched to an open abdominal surgery. Therefore, further study is needed to establish the feasibility of the use of a laparoscopic repair for severe $\mathrm{OH}$ cases.

In conclusion, laparoscopic surgery in simple $\mathrm{OH}$ patients was feasible. And when we determine the most advantageous preoperative surgical method and plan the operation efficiently, the decision can be made by taking into account WBC and CRP figures.

\section{ORCID}

Jae Seung Kwak, https://orcid.org/0000-0003-1480-562X

Sang Eok Lee, https://orcid.org/0000-0002-9956-7693

Seung Jae Lee, https://orcid.org/0000-0002-3302-6624

Seong Uk Kwon, https://orcid.org/0000-0003-3167-7527

In Eui Bae, https://orcid.org/0000-0002-9220-8815

Nak Song Sung, https://orcid.org/0000-0002-7549-3829

Ju Ik Moon, https://orcid.org/0000-0002-8120-5854

Dae Sung Yoon, https://orcid.org/0000-0002-6447-2862

In Seok Choi, https://orcid.org/0000-0002-9656-3697

Won Jun Choi, https://orcid.org/0000-0003-0788-7700

\section{AUTHORS' CONTRIBUTIONS}

Conceptualization: Sang Eok Lee. Formal analysis: Jae Seung Kwak. Methodology: Sang Eok Lee and Jae Seung Kwak. Writing-original draft: Jae Seung Kwak. Writingreview and editing: Sang Eok Lee, Jae Seung Kwak, Si Min Park, Seung Jae Lee, Seong Uk Kwon, In Eui Bae, Nak Song Sung, Ju Ik Moon, Dae Sung Yoon, In Seok Choi, and Won Jun Choi.

\section{CONFLICT OF INTEREST}

None.

\section{FUNDING}

None. 


\section{ACKNOWLEDGMENTS}

None.

\section{REFERENCES}

1) Mantoo SK, Mak K, Tan TJ. Obturator hernia: diagnosis and treatment in the modern era. Singapore Med J 2009;50:866-870.

2) Lo CY, Lorentz TG, Lau PW. Obturator hernia presenting as small bowel obstruction. Am J Surg 1994;167:396-398.

3) Nasir BS, Zendejas B, Ali SM, Groenewald CB, Heller SF, Farley DR. Obturator hernia: the Mayo Clinic experience. Hernia 2012;16:315-319.

4) Yokoyama Y, Yamaguchi A, Isogai M, Hori A, Kaneoka Y. Thirty-six cases of obturator hernia: does computed tomography contribute to postoperative outcome? World J Surg 1999;23:214216; discussion 217.

5) Hodgins N, Cieplucha K, Conneally P, Ghareeb E. Obturator hernia: A case report and review of the literature. Int J Surg Case Rep 2013;4:889-892.

6) Kohga A, Kawabe A, Okumura T, Yamashita K, Isogaki J, Suzuki K. Laparoscopic repair is a treatment of choice for selected patients with incarcerated obturator hernia. Hernia 2018;22:887-895.

7) Deeba S, Purkayastha S, Paraskevas P, Athanasiou T, Darzi A, Zacharakis E. Laparoscopic approach to incarcerated and strangulated inguinal hernias. Jsls 2009;13:327-331.
8) Deeba S, Purkayastha S, Darzi A, Zacharakis E. Obturator hernias: A review of the laparoscopic approach. J Minim Access Surg 2011;7:201-204.

9) Dundamadappa SK, Tsou IY, Goh JS. Clinics in diagnostic imaging (107). Singapore Med J 2006;47:89-94; quiz 95.

10) Khaladkar SM, Kamal A, Garg S, Kamal V. Bilateral obturator hernia diagnosed by computed tomography: a case report with review of the literature. Radiol Res Pract 2014;2014:625873.

11) Hayama $S$, Ohtaka $K$, Takahashi $Y$, Ichimura T, Senmaru N, Hirano S. Laparoscopic reduction and repair for incarcerated obturator hernia: comparison with open surgery. Hernia 2015;19:809814.

12) Liu J, Zhu Y, Shen Y, et al. The feasibility of laparoscopic management of incarcerated obturator hernia. Surg Endosc 2017;31:656-660.

13) Ng DC, Tung KL, Tang CN, Li MK. Fifteen-year experience in managing obturator hernia: from open to laparoscopic approach. Hernia 2014;18:381-386.

14) Ramser M, Messmer AS, Zbinden I, Von Holzen U, Nebiker CA. Incarcerated obturator hernia-laparoscopic repair with intraoperative view of the corona mortis. J Surg Case Rep 2014;2014:rju081.

15) Wu TC, Lu Q, Liang XH. Efficacy of emergency exploratory laparotomy in incarcerated obturator hernia. Acta Chir Belg 2018;118:105-109.

16) Chen $D$, Fei $Z$, Wang $X$. Bowel obstruction secondary to incarcerated obturator hernia. Asian J Surg 2017;40:193-196. 